\title{
ПРАВО И МОРАЛЬ: ИСТОКИ СОЮЗА
}

\begin{abstract}
Аннотация: Автор статьи размышляет о движущих факторах социального развития. В полемике с участниками дискуссии, которая ведется на страницах "Литературной газеты», он настаивает на том, что в перечне движущих сил современного прогресса нельзя не учитывать экономические интересы. Опираясь на современные труды видных экономистов, автор показывает, что идея ценности интересов имеет продолжительную историю. Многие европейские мыслители настойчиво и отчаянно критиковали человеческие страсти как жертвы аморальности. Алчность и накопительство оценивались как пороки. Однако постепенно эта критика переросла в своеобразную апологию эгоистических интересов. Этот общественный перелом в настроениях и привёл, в конечном счете, к появлению капитализма и его своеобразного триумфа. Различные современные трактовки капиталистической конкуренции вызывают подчас консервативные настроения, идеализацию времени "человеческих страстей», когда существовало определённое волшебство мира. Однако современный мир невозможен без идеи предпринимательства, конкуренции, эгоистических интересов. Таким образом, для усиления социальной динамики важны три фрактора-экономические интересы, право и мораль, то есть ценностные ориентации.

Метод анализа связан с принципом историзма. Автор стремится показать, как в истории европейской мысли мучительно осмысливались эти вопросы в тех или иных исторических условиях. Вместе с тем исследователь опирается на аксиологические принципы. Он, таким образом, анализирует современные ценностные ориентации. Наконец, в статье использованы методы феноменологии, которые позволяют выявить сущность базовых основ юриспруденции.

Новизна статьи в содержательном критике тех авторов, которые, во-первых, упускают из виду ключевую роль экономических интересов в динамике современного мира. Автор также оспаривает идею контроверзы ценностей и права. Попытка выбрать из этой пары какой-то один фактор, который будто бы обладает неоспоримой эффективностью, неверны. На самом деле для общественного развития важно не противостояние ценностей и закона, а их союз, совместная направленность на идею прогресса. Автор показывает, что апелляция к истории политических и юридических идей неоспоримо подтверждает это положение. Таким образом, стабильность общества зависит не от усиленной опоры на один из названных факторов, а на сбалансированное их использование.
\end{abstract}

Ключевые слова: философия права, юриспруденценция, закон, политика, ценности, нормы, капитализм, глобализация, общественная динамика, нравственность.

\section{Интересы и страсти}

«Литературная газета» продолжает обсуждать напечатанную в ней статью акад. В. Иноземцева «Не ценности, а нормы». Автор утверждал, что для развития современного общества особое значение имеет право. Между тем, по его мнению, в России нет должной опоры на закон. Больше внимания уделяется ценностям. Это кажется академику неверным. Он в своей статье показывает, что ценности не столь конкретны и прозрачны, как законы. Поэтому важно укреплять законность, а не отвлеченные жизненные и практические установки.
Статья В. Иноземцева, безусловно, нашла сторонников. Это неудивительно - нам до сих не удалось создать правовое общество, в котором четко определены правила бизнеса, общественных отношений в социуме, регулятивные механизмы хозяйствования. - Многим кажется, что обсуждение нравственных основ экономики в условиях, когда не проработаны и не задействованы правовые нормы, по сути дела, отвлекает общество от наиболее значимых проблем.

Не все в ходе дискуссии приняли точку зрения В. Иноземцева. Так, Татьяна Воеводина в «Литературной газете» пишет: «Закон и ценности - это 


\section{Философия и культура 12(84) • 2014}

дом и фундамент. Ценности - фундамент, закон строение, которое на нём возведено. Если в основе закона лежат чуждые народу ценности - такой закон никогда не будет прочен, и не будет выполняться. Не обязательно дело придёт к бунту, хотя и так бывает, но ползучее игнорирование закона, нарушение, где только можно, - это гарантировано. Законы вырастают из правил поведения, распространенных в народе: морали, житейских норм, правовых обычаев» ${ }^{1}$.

Верно подмечено, что законы и нравственность связаны между собой. Однако сама эта связь, по нашему мнению, представлена односторонне. Можно ли утверждать, что законы выражают общественное сознание, дух народных представлений? Эта мысль верна только в отвлечённом, теоретическом плане. Но подкрепляется она в статье не социальными примерами, а философскими и политическими аргументами. Да, Гегель писал, что государство - это обретший форму народный дух ${ }^{2}$. Но в реальной исторической практике закон и требования общества далеко не всегда совпадают. Требуется особая мудрость законодателей, чтобы привести в соответствие законы и житейские нормы, правовые обычаи. Если бы это считалось непреложным, не было ни революций, ни бунтов, ни реформ.

Приведем такую историческую ссылку. Генрих IV стал королем Франции в 1600 г. Он застал правосознание страны в таком виде, которое никак не выражало общественные настроения или тем более дух народа. Размер государственного долга в стране на момент его прихода к власти превышал 348 млн. ливров. Франция переживала глубокое социальное расслоение. Но существующее право, выражавшее интересы аристократии, полагало, что это справедливо. Как же избавить страну от долгов? Аристократы считали, что надо увеличить налоги с простых людей. Король мог узаконить такое положение вещей, которое соотносилось с интересами богатых людей. Но Генрих IV считал, что это несправедливо. Король не просто искал удобное решение, которое позволило бы выйти из кризиса. Он полагал, что существующее в стране право чревато катастрофой. Генрих IV, которого потом стали называть величайшим королем Франции, исходил из того, что «все люди рождаются равными и сво-

1 Воеводина Татьяна. Право и душа // Литературная газета. 2014. 04 июня. № 22(6465). С. 9.

2 Гегель Г. Философия права. М.: Мир кн.: Лит., 2009. бодными и имеют право на счастье». Поэтому он привел законодательство в соответствие с интересами народа, а мог бы поступить иначе.

Татьяна Воеводина в своей полемической статье «Право и душа» подкрепляет свои рассуждения скорее в жанре спасительного идеала. Конечно, немецкие учёные так называемой исторической школы права в первой половине XIX в. рассуждали о том, как важно, чтобы позитивное право было связано с народным духом. Тем более, что воочию убедились в том, что нарушение этой связи привело к трагедии Французской революции. Гуго, Пухта, Савиньи уже не сомневались в том, что революция неизбежна, если юридические установления не соответствуют ни народной психологии, ни правовым обычаям. Справедливо замечание Татьяны Воеводиной: «Правоведы исторической школы считали, что юридическая система - сродни языку: это и социальное явление и - одновременно - природное, никем не выдуманное и не сконструированное» ${ }^{3}$.

Однако и сама статья В. Иноземцева и ее оппоненты почему-то заняты поиском наиболее верной, но единственной скрепы общественной жизни. Они хотят в конкретной исторической ситуации опереться либо на закон, либо на мораль. Однако такой подход в истории человечества постоянно оборачивался тем, что общественный организм испытывал тенденцию к «скособочиванию». Идеализация права, связанная с идеей «правового общества» без учёта нравственного климата, как единственный рычаг общественного развития неэффективен. В той же мере апология морали, не подкрепленная правом, не обеспечивает общественной динамики. В одном случае граждане, ощущая безнравственность законодательства, размышляют о том, как его обойти. В другом - бесконечные призывы к моральным решениям, не действенны, они зачастую вообще не получают законодательного оформления.

Но ошибочно, на наш взгляд, видеть в общественном развитии только эти две опоры. На самом деле их три, кроме права и морали в истории действуют еще и интересы. Социум стоит на этих трех китах: интересы, мораль, право. Представим себе ситуацию, когда законодатели приводят в действие морально обоснованные законы, но эти меры не отвечают социальным интересам. Много ли проку от такого эффективного союза? Координация

Воеводина Татьяна. Право и душа // Литературная газета. 2014. 04 июня. № 22(6465). С. 9. 
трех компонентов - интересов, закона и морали вот правильное решение проблемы общественной динамики. Поэтому если в обществе нет нужного правового строительства, но оно замещается размышлениями о морали, то это ненормально. В этом смысле акад. В. Иноземцев прав. Но без нравственного компаса правовое общество может не только деградировать, но и вообще ухнуть в пропасть.

Вот почему некоторые авторы, принявшие участие в дискуссии, выступают в защиту ценностей, «обиженных» В. Иноземцевым. Так, Е. Устименко в заметке «Неистребимые фикции» отмечает, что ценности остаются в общественном сознании даже тогда, когда власть и действующие в обществе отношения в полной мере не способствуют их соблюдению» ${ }^{4}$. В самом деле, В. Иноземцев полагает, что в Европе, где властвует право, а не ценности, общество чувствует себя замечательно. Можно подумать, будто в Европе нет коррупции, преступности, самоубийств? Не вполне корректно также сравнение мусульманских и христианских ценностей, данное В.Иноземцевым. Получается, будто мусульманские ценности лучше западных, поскольку ближе к законам. Е. Устименко справедливо замечает: «Нормы и ценности - разные средства упорядочивания общественной жизни. Нормы, особенно правовые, однозначны и охватывают далеко не все моменты социальных отношений, особенно если вести речь о тонких и деликатных моментах в жизни человека. Сведение всех процессов в обществе к государственно-юридически оформленной системе не способно отразить всей жизни» ${ }^{5}$. Тем более, что ценности и нормы историчны, они преобразуются соответственно культурным и цивилизационным преобразованиям. Поэтому они могут оказаться чуждыми народам, особенно если они «внедряются» насильственно.

Ценности всегда избирательны. Разумеется, в каждом обществе есть общепринятые святыни. Однако каждый гражданин волен принимать или не принимать эти ценности. Отступление от тех ценностей, которые в данном социуме приняты, не являются преступлением. Попытки «втиснуть» ценности в правовой поле, закрепить их в общественном сознании, в большинстве случаев, либо курьёзны, либо утопичны. Вот, скажем, пушкинское «любовь к отеческим гробам, любовь к род-

\footnotetext{
4 Устименко Е. Неистребимые «фикции» // Литературная газета. 2014. 02 июля. № 26(6469).

5 Там же.
}

ному пепелищу». Ценность не подлежит правовой оценке. Можно ли вводить какие-то нормативы в естественном, но необязательном стремлении людей помянуть умерших родственников? Между тем право не оставляет пространства для свободного выбора. Поэтому невозможно законодательство закрепить такие ценности, как патриотизм, человеческое достоинство, почитание родителей. Эти ценности не получают директивной опоры, но могут укорениться в обществе благодаря воспитанию, идеологической работы.

Следовательно, став на путь тотального укрепления только права, как советует В. Иноземцев, любое общество, в том числе и наше, понесло бы ущерба, а не получило бы надежный рычаг для усиления экономического или социального роста. Всякое противопоставление ценностей и норм имеет негативный заряд. Но самое главное - эта проблема, которую «Литературная газета» предложила для актуального обсуждения, возникает не впервые. Начиная с античных времен, политики и философы размышляют о том, как соотнести различные факторы общественного развития в некую систему, способную гармонизировать общественные связи. К этой цели была направлена философия в Греции, право в Риме. «При взгляде на римский бюст, - пишет немецкий философ Вильгельм Дильтей, - считающийся изображением Сципиона, Африканского, нас поражает массивность и мощь прирожденной королевской воли, которая как бы подавляет все находящиеся вблизи греческие лица. То же массивное властное достоинство выражено в своде масс римского Пантеона, в Трирской Porta nigra или в языке Двенадцати таблиц, оно все еще ощущается даже в стихах Вергилия и в стиле Тацита» ${ }^{6}$.

В Риме, как показывает В. Дильтей, вся жизнь подчинена некоей целостности. Вырабатываются правила господства над жизнью. Оно распространяется на земледелие, хозяйство, семейную жизнь, право, военное дело, управление государством. В соответствии с этим принципом интересы людей подчинены правилу и идее целостности. Своей вершины этот римский дух достигает в создании самостоятельного права и самостоятельной юриспруденции. Речь идёт прежде всего о законных интересах людей, которые хотят, чтобы их стремления были поддержаны законодательно.

\footnotetext{
6 Дильтей Вильгельм. Воззрение на мир и исследование человека со времен Возрождения и Реформации. М., Иерусалим, 2000. С. 13.
} 


\section{Философия и культура 12(84) • 2014}

\section{Интересы и страсти}

Нет сомнений в том, что капитализм обязан своему триумфу, прежде всего, реализацией экономических интересов. Без них ни мораль, ни право сами по себе не привели бы к многовековому господству этой формации. В докапиталистическую эпоху преследование материальных интересов в течение длительного исторического времени осуждалось как смертный грех алчности. О радикальном изменении интеллектуального климата XVII-XVIII вв. рассказывает в своей книге выдающийся американский экономист О. Хиршман. Его работы оказали огромное влияние на специалистов, преобразив понимание экономического развития и роли социальных институтов в нём. Его исследование позволило другими глазами увидеть, в чём состоит идеологическое обоснование капитализма7.

Автор этого исследования в свое время вдохновился идеей известного социолога Ш. Монтескьё о том, что хотя человеческие страсти способны привести человека к безнравственному поведению, все же есть фактор, который способен остановить действие этих пагубных устремлений. Это социальный интерес. Эгоистическая природа человека способна прервать всесилие демонических страстей, в том числе и властолюбия. Историческая практика показывает, что стяжание и рыночные отношения позволяют искоренять злоупотребление властью. Порой экономическое чудо, которого добиваются отдельные страны, объясняется не последовательным проведением экономических интересов, а лишь утверждением определенных ценностных ориентаций. Так, ряд экономистов считают, что экономические успехи стран Восточной Азии были обусловлены в основном ценностными ориентациями этого региона, уважением к «порядку», «дисциплине», «лояльности». Примеры, которые относятся к Японии, были затем распространены и на других «тигров». Увлечение конфуцианской этикой, самурайской культурой привело к тому, что мотивационные вариации учения М. Вебера о протестантской этике стали порой казаться странным атавизмом.

Экономическая динамика немыслима без обоснования различных теорий сблансированного роста. Апелляция к роли экономических интересов не отвергает других факторов общественного раз-

7 Хиршман О. Страсти и интересы. Политические аргументы в пользу капитализма до его триумфа. М., 2012. вития. Хиршман в своей работе пытается понять, каким образом предпринимательская деятельность, которая в лучшем случае воспринималась лишь как допустимая, превратилась в призвание? Как случилось, что коммерческая активность, банковское дело, которые в Новое время оценивались как выражение жадности, алчности, стали не просто допустимыми, но и почетными. Дух капитализма находил своих приверженцев среди купцов уже в XIV-XV вв. Однако еще при начале христианской эры Августин Блаженный, представивший своеобразный путеводитель по средневековому мышлению, назвал алчность похотью и расценил как один из основных грехов падшего человека (к ней примыкали властолюбие и сексуальная одержимость). Августин Блаженный не исключал, что один порок способен сдерживать другие пагубы. Скажем, жажда славы может заместить стремление к алчности. Стяжание славы как предназначения жизни одушевляло в XVII в. трагедии Корнеля.

В основе своей этой поворот, как нам кажется, связан с попытками философского постижения человека. Новая этика, которая формировалась в эпоху Возрождения, была занята уже не обоснованием правил поведения, которые предлагались индивиду. Мыслители были озабочены тем, что поставить на должную основу возможности государственного управления. Но как решить эту задачу, не имея должного представления о человеческой природе? Эту проблему хорошо осознавал, судя по всему. Н. Макиавелли. Однако ему не удалось систематизировать свои отдельные суждения по этому поводу. Этот политик считал человека силой природы, источником живой энергии. Основная его мысль сводилась к осознанию единообразия человеческой природы. Ее невозможно изменить произвольно, по своей прихоти. Все люди, полагал он, обладают одинаковыми страстями, которые приводят к одному и тому же действию. Сама идея эволюции человечества, развития человека была чужда Макиавелли. Эти представления в XVI в. привели к обоснованию тезиса о том, что все культурные формы выводятся в конечном счете из человеческой природы.

Макиавелли с поразительной наблюдательностью коллекционирует влечения и аффекты человека, его страсти. Он приходит к убеждению о безграничности и ненасытности человеческих вожделений. Разумеется, считал он, можно диагностировать механизм влечений, азартную игру страстей. Они всегда неизменны, как и человеческая природа. 


\section{Философия права}

Что же касается морали, то она существует только в умах проповедников. Нравственность, конечно, диктует основные законы и правила коллективной жизни. Но они не вытекают из человеческой природы. Можно назвать лишь одну творческую способность - волю к господству, которая позволяет регулировать действие страстей и эффектов.

Таким образом, в эпоху Возрождения «возникло, а в XVII в. окончательно укрепилось чувство того, что морализаторская философия и религиозные предписания уже не в силах быть надежными инструментами сдерживания пагубных страстей человека» ${ }^{8}$. Именно поэтому страсти подверглись в этом столетию тщательному изучению. Пафос исследования заключался в том, чтобы претворить разрушительные страсти в нечто конструктивное. Кое-что в этом отношении уже удалось. В начале XVIII в. Джамбаттиста Вико пишет: «Так из свирепости, скупости и честолюбия (эти три порока пронизывают насквозь весь род человеческий) оно (имеется в виду государство - Р.П.) создает войско, торговлю и двор, т.е. силу, богатство и мудрость Государств. И из этих трех великих пороков, которые, несомненно, уничтожили бы поколение людей на земле, оно создает Гражданское Благополучие. Эта аксиома доказывает, что здесь присутствует Божественное Провидение; другими словами - Божественный Ум - Законодатель: из страстей людей, всецело преданных своим интересам, из-за которых они принуждены были бы жить, как дикие звери, в одиночестве он создает гражданские установления, и благодаря им люди живут в Человеческом Обществе» ${ }^{9}$

Сама идея, как приспособить страсти к тому, чтобы они вынуждены были работать на общее благо более основательно, была проработана Бернардом Мандевилем. Его считают основоположником концепции частного предпринимательства. В своем сочинении «Басни о пчёлах» он настаивает на умелом управлении искусного политика. Речь идет о том, как использовать частный интерес блага общества. Однако он нашёл в лице Адама Смита более последовательного и убеждённого экономиста, который пытался осветить проблему соотношения интересов и страстей. Немногие отдают себе отчет в том, что его работа «Исследование о природе и причинах богатства народов целиком

\footnotetext{
8 Там же. С. 42.

9 Вико Дж. Основания новой науки об общей природе вещей. М., Киев, 1994. С. 75.
}

посвящена такой человеческой страсти, как алчность или скупость. Он обострил проблему, стремясь уйти от религиозного проповедничества. Такие слова, как «страсть» и «порок» Адам Смит заменил на более нейтральные - «преимущество» и «интерес».

Однако многие философы продолжали изучать человеческие страсти, полагая, что они все-таки способствуют общему прогрессу. Поэтому главная идея либерализма XIX в. не стала сразу всеобщей. И это неудивительно, потому что осуждение человеческих страстей имело длительную историческую традицию. Средневековые авторы нередко прибегали к языку аллегорий, которые позволяли видеть схватки добродетелей со страстями в душе людей. В более позднее время речь шла о том, чтобы планомерно натравливать одну страсть на другу, тем самым ослабляя их действие с экономической теории. Б. Спиноза в работе «Этика» утверждал: «Аффект может быть ограничен или уничтожен только противоположным и более сильным аффектом, чем аффект, подлежащий укрощению» ${ }^{10}$. Эти концепции можно назвать принципом уравновешивания страстей. Он сложился в XVII в. и в течение длительного времени не позволял сформироваться идее экономических интересов. Известно, к примеру, что неистовым оправдателем страстей оказался П. Гольбах. В его книге «Об уме» есть даже такой отрывок, озаглавленный «О могуществе страстей». Он даже склонялся к мысли, что люди, захваченные страстями, гораздо умнее обыкновенных рассудительных людей. Гельвеций, в частности, писал: «Очень немногие моралисты умеют пользоваться нашими страстями, вооружая их друг против друга и тем самым заставляя нас согласиться с их взглядами; что только страсть может победить страсть. Например, для того, чтобы побудить легкомысленную женщину быть более сдержанной и стыдливой, надо ее кокетству противопоставить её тщеславие, внушить ей, что стыдливость изобретена любовью и утонченным сладострастием... Заменяя таким образом брань указаниями на собственный интерес, моралисты могли бы заставить принять своим правила» ${ }^{11}$.

Столь обстоятельное обсуждение человеческих страстей понадобилось нам для того, чтобы

10 Спиноза Б. Этика // Спиноза Б. Сочинения в 2-х тт. Т. 1. СПб., 1999. С. 400.

11 Гельвеций К.А. Об уме // Гельвеций К.А. Сочинения в 2-х тт. T. 1. М., 1974. С. 261-262. 


\section{Философия и культура 12(84) • 2014}

отметить, как категория экономического интереса возникла из длительной попытки мыслителей, экономистов и правоведов утвердить значимость самой идеи трудолюбия и бережливости. Постепенно оказалось, что слово «интерес» выполнило роль родового понятия для характеристики тех страстей, которые должны были уравновесить множество человеческих устремлений. Сначала обозначилась идея государственного интереса, а затем в социальную практику вошли уже частные и групповые интересы.

Почему экономический интерес обладает преимуществами по сравнению со страстями? Постепенно стало очевидно, что если в обществе доминирует интерес, то можно видеть в социальной практике предсказуемость и постоянство. Интерес, как говорится, в отличие от страстей, не обманет и не подведёт. Родилось представление о том, что если люди методически отстаивают и реализуют свои интересы, то это приводит к взаимной выгоде. Скажем, так называемая меркантилистская доктрина в период от Юма и Адама Смита считала, что в торговле люди используют свои интересы. Но это не означает, что в результате все выигрывают. Напротив, кто-то несёт убытки, тогда как другие соответственно получают выигрыш.

Однако в XVIII в. все-таки господствуют взгляды, позволяющие полагать, что расширение торговли, безусловно, оправдано для всех участников этой практики. В этом столетии возникло новые идеологические и экономические взгляды. Экономисты стали изучать психологические мотивы поведения людей. Не случайно Макс Вебер в своих работах показал, что все больше участников экономической практики стали приверженцами принципу рационального капиталистического накопления. Однако возникает вопрос, почему в исследованиях о социальном развитии категория «интереса» часто получала критическую трактовку, которая заметна и сегодня. Очевидно, потому что когда капитализм все-таки укрепился, мир утратил прежнюю привлекательность. Ведь об утрате романтического взгляда в мире чистогана писал и К. Маркс. Новому миру явно недоставало очарования, благородства, величия. Процесс «разволшебствования» жизни обрушил многие традиции, которые обладали привлекательностью, многим стало казаться, что прежняя эпоха была апофеозом целостности человеческой личности.

В наши дни социальные критики обратили внимание на многие кризисные процессы совре- менного общества. Они пытаются найти альтернативу экономической практике, в основе которой лежит интерес. Многие мыслители стремятся обозначить другие стимулы человеческого поведения, возродить страсти, которые придавали общественному развитию особый колорит. Однако мир сегодня стоит на экономических интересах. Нет сомнений в том, что дальнейшее развитие правосознания, укрепление аксиологических основ современного общества обладают мощной силой. Однако без учёта экономических интересов людей и государств картина нынешней эпохи будет односторонней. Мы видим, как многие страны положили в основу своей глобалистской политики неуклонное, подчас даже агрессивное соблюдение собственных государственных интересов. Им при известных условиях подчиняются ценностные ориентации и даже правовые установления. Поэтому нет сомнений в том, что дискуссия, которая началась в «Литературной газете», обращена к политикам, экономистам, юристам. Необходимость угадывать в общественном сознании царящие в нём ценностные ориентации и увязывать их с ядром народной жизни, настоятельно важна. Ведь идея правового общества, выношенная в трудах Ж.-Ж. Руссо, исходит из представления о том, что всем гражданам мира мила мысль о неотъемлемых правах человека. Однако процесс глобализации, который должен был подтвердить универсальную тягу к демократии, натолкнулся на глубокие антиглобалистские тенденции. Согласно приверженцам глобализма нет никакой причины разглядывать в общественной практике отражение народного духа, особенности цивилизационной жизни. Принципы демократии и прав человека универсальны и не зависят от исторического времени. Но события на международной арене свидетельствуют о том, что отступление от союза морали и права, акцентирование лишь одной стороны этого процесса приводят к серьезным политическим и экономическим процессам. Это позволяет еще раз обратиться к истории социальной мысли.

\section{Естественный нравственный закон}

В данном случае важно раскрыть историю нравственных законов, на которых строится юридическая практика. О том, как формировалась протестантская этика, немало. Обратимся к учению немецкого гуманиста, теолога и педагога, деятеля Реформации Филиппа Меланхтона (1497-1960). 
Его наследие, на наш взгляд, не получило должной оценки и анализа. Цель многочисленных интеллектуальных усилий этого человека сводилась к нравственному облагораживанию Германии. Он задумывался о моральном преображении мира. Меланхтон был убежден в том, что любое юридическое действие должно опираться на моральные установления. При этом он опирался на философию античных стоиков. Он заимствовал у них идею общих понятий, которые могли бы определять законы. Дело в том, что стоики считали общие понятия «врожденными», а итогом познавательной деятельности человека.

Меланхтон связал учение Аристотеля о принципах со взглядами Цицерона о естественном свете. Идея Бога выводилась им из нравственного закона в душе человека. Высшее отражение этого закона - различение добра и зла. Мыслитель полагал, что формирующие силы общества нерасторжимо связаны с нравственными идеями. Им должно быть подчинено общество, государство и право. Все социальные добродетели, по мнению Меланхтона, находят кристаллизацию в понятии справедливости. Он толкует это понятие как один из принципов, которые определяют добрые взаимные отношения между людьми. Со времен Аристотеля существовало разделение справедливости на распределяющую и уравнивающую. В одном случае речь о количественном распределении имеющих благ без учета тех достоинств, которыми они обладают. В другом варианте заложена мысль о том, что люди неодинаковы по своим задаткам, положению и общественной полезности.

В основе учения Меланхтона лежит позиция Аристотеля, который усматривал справедливость в первую очередь в том, что поддерживается послушанием законам государства во всем их объеме. Вслед за римскими юристами немецкий теолог полагал, что закон выражает твёрдую, постоянную волю, позволяющему каждому получить то, что ему причитается. Такого рода справедливость выводится из велений природы. В то же время эти принципы коренятся в божественном духе. Действия людей обусловлены нормами, которые как раз и позволяют различать добро и зло. Эти установления определяют как всю правовую и государственную жизнь, так и правила поведения отдельного человека.

У Меланхтона проводится различие между естественными правом и нормами позитивного права. Позитивное право поддерживается авто- ритетом правительства и ресурсами разума. Оно обеспечивается декретами легитимной власти. Данное сопоставление естественного и позитивного права имеет немалое историческое значение. Однако Меланхтон еще не проводит маркировку между нравственными законами и правовыми положениями. Нельзя сказать, что ему удалось развить основополагающие понятия юриспруденции. Но он привел в соответствие толкование римского права с эпохой Реформации. Меланхтону удалось отстоять положение о том, что римское право не просто свод установление, но еще и своеобразная философия.

Немецкому теоретику не удалось в полной мере провести различие между сущностью права и морали. Однако он отыскал обоснование важным правовым институтам собственности, брака, а также пенитенциарной системы и власти. Он видел их предназначение в защите порядка в обществе. Вместе с тем в правосознание входит идея, согласно которой подданные имеют право противостоять государственной власти в случае если она злоупотребляем правом. Если власть нарушила естественные принципы, ее подданные имеют право на сопротивление.

В русле нашей темы важно, что Меланхтон утверждает нравственную ценность предпринимательской деятельности. В этом смысле он негативно отзывался о жизни монахов, призывая к подлинному почитанию Бога, которое он видел именно в служении труду, а не созерцанию. Меланхтон считал, что благочестие не позволяет многим активным служителям церкви проявить свое трудолюбие, инициативу, предприимчивость. В результате обнаруживается расхождение между религиозным идеалом и мирской повседневностью. Лютер и Меланхтон стремились устранить этот разлад. Правда, в основном это касалось чисто доктринальных вопросов. В сфере практической деятельности существенных подвижек не было.

Меланхтон полагал, что наличие собственности и возможность ее распределения реализуется с помощью эгоистических устремлений людей. Но это не противоречит божественным принципам. Немецкий ученый оправдывает приобретательство. Более того, он считает эти действия добродетельными. Отметим также, что теология Меланхтона была напрямую связана с протестантским этосом. После выхода в свет книги Меланхтона «Вероучение» Лютер признал ее близкой к книгам Священного Писания. Главное положение это- 


\section{Философия и культура 12(84) • 2014}

го общего учения - признание достоинства труда, который без свершения немыслим. Иначе говоря, труд освящается действующей силой, достижением конкретных и очевидных результатов человеческой активности.

Каков же общий итог данной интеллектуальной деятельности вождей Реформации относительно союза морали и закона? Они показали, что принципы естественного права помогли расшатать старое общество. Однако следовало еще создать новый строй. Активность естественной системы проявилась в преображении правового порядка в духе римской юриспруденции. Переход к свободной промышленности и торговле предполагал распространение капитала. Этот процесс начался уже в эпоху Возрождения. Основываясь на римской юриспруденции, которая даровало свободу личности в области права и собственности. Договор, который оправдывался суверенно действующей волей, стал основной формой всех правовых отношений.

Как же осмысливались и разрешались противоречия в социальной и политической сфере? Чтобы гражданское общество приобрело динамику и развитие, нужны были новые основания. Разумеется, отыскать их в теократических идеях средневековья было немыслимо. Любое обращение к древности, в частности, к римской юридической практике, к системам имперского управления наталкивалось на пределы, которые отделяли прежний мир от нового, рождающегося. Именно по этой причине античные юридические и политические концепты нуждались в преображении, в корректировке, в дальнейшей разработке. Возникает идея правового равенства всех подданных. В общественном сознании рождается убеждение, что природа дала всем людям совместную среду обитания, не приговорив никого из них к рабству. Религиозные войны требовали установления неотчуждаемых прав всех людей.

Мыслители новой эпохи считают, что властители не имеют оснований для нарушения божественных законов. Если это происходит, подданные имеют право на сопротивление. Основами общественной жизни провозглашается семья (в ее римском толковании), личная свобода, частная собственность и готовность личности соблюдать частно-правовые обязательства. Стало быть, в божественных и естественных законах, в самой сути правовых условий, без которых невозможно ни одно государство, можно обнаружить и превыше- ние власти. Французский политический деятель Жан Боден (1530-1596) оспаривает универсальность послушания. Если суверен пренебрегает установлениями божественного закона и велений природы, то граждане вправе не подчиняться его воле и политике. На этой основе Боден настаивает на отделении правосудия от правительства. Он считает государственный договор фундаментом государственного права. Иначе говоря, власть политика не беспредельна. Она покоится на соблюдении или несоблюдении неких предусловий. Так, Боден, кстати, поборник монархических идеалов Генриха IV, отстаивает идею суверенности. Он был против любого деления государственной власти. Боден отвергает понятие смешанных государств. Таким образом, суверенностью наделяется народ. Обосновывая сущность идеи суверенности, Боден вооружается латинским утверждением: «Правитель не ограничен законом». Но Жан Боден одновременно ссылается на учение Аристотеля о государственных формах. Более того, он развивает дальше представления об этих формах с учётом накопленного политического опыта. При создании того или иного государства важны многочисленные факторы - географическое положение, традиции, психология людей. Рассматривая эти факторы, Боден раскрывается как социолог значительного масштаба, как предтеча Ш. Монтескьё.

Личная позиция Бодена - отстаивание идеи монархии. Он полагает, что только при этом политическое режиме можно должным образом сочетать и последовательно проводить демократический принцип равенства всех людей. Но учитывать также роль аристократии, без которой невозможно правильное распределение функций и прав в государстве. Боден, стало быть, думал о том, как соединить те положительные свойства, которыми отличается демократия и аристократия, но при этом не допускать деление властей. Если руководствоваться только демократическим принципом, то у народа окажется явное преимущество. Но для соблюдения единства правительства, в нём должны быть и представители элиты.

\section{Моральный и правовой мир}

Татьяна Воеводина, принявшая участие в дискуссии о противостоянии правовых норм и ценностей, сослалась, в частности, на труды Гуго Гроция. Но этот голландский юрист и государственный деятель и не помышлял о конкуренции права и морали. Он стре- 
мился укрепить статус политики и права. Главенствующая тенденция этого времени состояла в том, чтобы эти понятия оказывали решающее влияние на общественное устройство. Причем эта идея получила в работах Гуго Гроция классическое обоснование. Гроций, как и другие авторы, обращается к учению стоиков. Именно в этих трудах он ищет обоснование морального и политико-правового мира. При этом Г.Гроций выступает и как религиозный мыслитель. Он оспаривает идею жертвенности, на которой покоится христианство. Подлинный смысл этой религии, по мнению Г. Гроция, достижение блаженства, а не мучений.

Основываясь на общей юриспруденции, он стремится развить контуры международного права. Свои усилия он направляет на обозначение базовых основ права, которые уже не выводятся не из каких других правил. Эти основы он называет непоколебимыми, которые невозможно отрицать, не прибегая к самообману или насилию. Они, по его словам, столь же очевидны, как показания органов чувств, на которых строится дальнейший ход познания. Стало быть, метод дедукции выступает в данном случае как методологический принцип, позволяющий «вывести» конкретные положения международного права из общезначимых понятий, имеющих неоспоримый характер. Метод Гроция можно охарактеризовать как юридическую конструкцию. По существу, основные элементы международного права Г. Гроций заимствует из естественного права.

Но Г. Гроций рассматривает также и деление права в целом. Отправляясь от различения естественного и позитивного права, принятое древними, он пытается дать этому различению дробное истолкование. В позитивном праве, по мнению Г. Гроция, доминирует волевое полагание. Оно может исходить из воли отца, сюзерена, а также из воли гражданской власти и согласованного решения ряда наций. В основе таких решений лежит согласие. Но речь идет не о разнообразии субъективного произвола. Договор все равно обусловлен естественным правом. Поэтому непреложность его соблюдения Г. Гроций рассматривает как мать гражданского права.
Эти идеи Татьяна Воеводина приписывает почему-то Ж.-Ж. Руссо. Г. Гроций выступает у неё как мыслитель, который ищет обоснование политических решений в народном духе. Но апелляция Г. Гроция к естественному праву носит другой смысл. Он обосновывает объективность, универсальность этого права. Таким образом, институты собственности, ценности и обязательность договорных обязательств складываются, формируются, независимо от воли людей. У Г. Гроция юриспруденция опирается на такие понятия и утверждения, которые неотвратимы. Они присущи всем людям. Если бы они не проистекали из природы вещей, то правовой порядок был бы зыбким. В известной мере на этих принципах основана и идеология глобализма. Как уже отмечалось, глобалисты уверены, что во всех регионах мира люди одинаково относятся к ценностям демократии, равенства прав всех людей, независимо от их происхождения и заслуг.

Заслуга Г.Гроция состоит в том, что он не считает юридические положения продуктом аналитической мысли. Напротив, он рассматривает их как понятия самой жизни. Хотя Гроций, как и другие юристы, в поисках обоснования права, обращается к римским стоикам, он все-таки соотносит их с реалиями новой эпохи. Это особенно впечатляет, поскольку Гроций не абсолютизирует идею пользы. Он полагает, что общезначимые элементы права не имеют лишь прагматическое происхождение, связаны с достижением полезности. Многие опоры юридических прав он выводит из социального инстинкта человека, из его общественной природы. Он признает также человеческое свойство - создавать правила, согласно которым протекает его бытие.

Завершая анализ проблемы, можно сказать, что соотношение права и морали, как показывает проведенное исследование, не является ситуативной проблемой. Иначе говоря, не следует думать, будто именно сегодня возникает потребность сделать ставку на закон или нравственность, чтобы остальные мучительные проблемы сразу получили разрешение. Данная тема имеет серьезное историческое и проблемное измерение.

\section{Список литературы:}

1. Вико Дж. Основания новой науки об общей природе вещей. М., Киев, 1994.

2. Воеводина Татьяна. Право и душа // Литературная газета. 2014. 04 июня. № 22(6465).

3. Гегель Г. Философия права. М.: Мир кн.: Лит., 2009.

4. Гельвеций К.А. Об уме // Гельвеций К.А. Сочинения в 2-х тт. М., 1974. Т. 1. 


\section{Философия и культура 12(84) • 2014}

5. Гуревич П.С. Философская интерпретация человека (К 80-летию проф. П.С. Гуревича). СПб.: Петроглиф, 2013.

6. Гуревич П.С. Этика. 2-е изд., перераб. и доп. М.: Юрайт, 2013.

7. Дильтей Вильгельм. Воззрение на мир и исследование человека со времен Возрождения и Реформации. М., Иерусалим, 2000.

8. Спиноза Б. Этика // Спиноза Б. Сочинения в 2-х тт. СПб., 1999. Т. 1.

9. Устименко Е. Неистребимые «фикции» // Литературная газета. 2014. 02 июля. № 26(6469).

10. Хиршман О. Страсти и интересы. Политические аргументы в пользу капитализма до его триумфа. М., 2012.

\section{References (transliteration):}

1. Viko Dzh. Osnovaniya novoi nauki ob obshchei prirode veshchei. M., Kiev, 1994.

2. Voevodina Tat'yana. Pravo i dusha // Literaturnaya gazeta. 2014. 04 iyunya. № 22(6465).

3. Gegel' G. Filosofiya prava. M.: Mir kn.: Lit., 2009.

4. Gel'vetsii K.A. Ob ume // Gel'vetsii K.A. Sochineniya v 2-kh tt. M., 1974. T. 1.

5. Gurevich P.S. Filosofskaya interpretatsiya cheloveka (K 80-letiyu prof. P.S. Gurevicha). SPb.: Petroglif, 2013.

6. Gurevich P.S. Etika. 2-e izd., pererab. i dop. M.: Yurait, 2013.

7. Dil'tei Vil'gel'm. Vozzrenie na mir i issledovanie cheloveka so vremen Vozrozhdeniya i Reformatsii. M., Ierusalim, 2000.

8. Spinoza B. Etika // Spinoza B. Sochineniya v 2-kh tt. SPb., 1999. T. 1.

9. Ustimenko E. Neistrebimye «fiktsii» // Literaturnaya gazeta. 2014. 02 iyulya. № 26(6469).

10. Khirshman 0. Strasti i interesy. Politicheskie argumenty v pol'zu kapitalizma do ego triumfa. M., 2012. 